\title{
Manuel João Monte - Em Palco
}

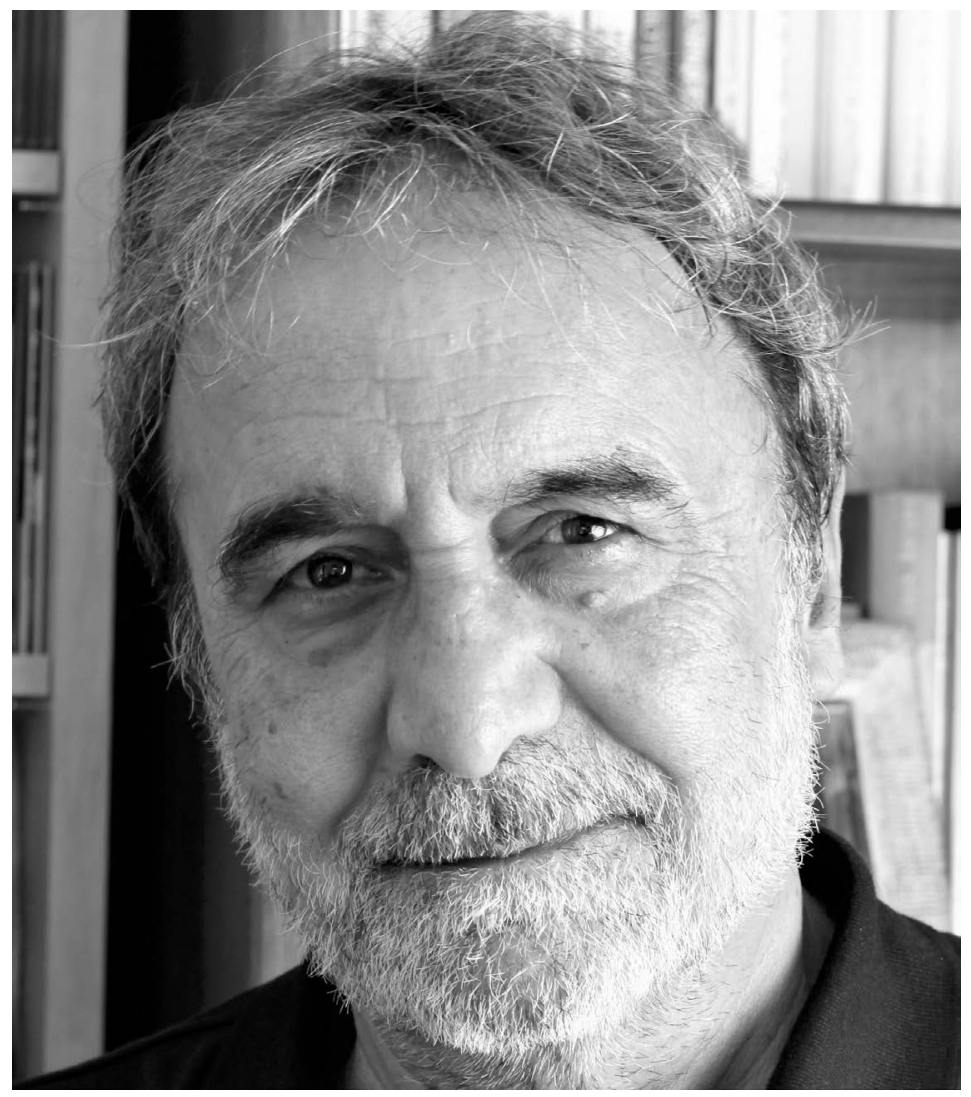

Interação Química com

Maria José Lourenço

Manuel João Monte

mjlourenco@ciencias.ulisboa.pt

0 teatro é um lugar para representar comédias, tragédias, farsas, revistas... onde se exprimem emoções, onde acontecem cenas. A Interação Química conversou com o autor da divertida peça de teatro O Bairro da Tabela Periódica, galardoado com a 3.” edição do prémio José Mariano Gago da Sociedade Portuguesa de Autores. Nesta paródia envolveram-se 118 vedetas, discutiu-se a igualdade de género e fez-se o retrato de reuniões de condomínio, numa representação lúdica com conteúdos sérios. Sem maquilhagem, com o som, a iluminação e a cenografia de uma sessão Zoom, estivemos à conversa com o "ator" Manuel João Monte. Nesta interação insistimos na importância de se corrigir o engano que "ser químico = mau" e "ser natural = bom". Para ensinar química com sucesso há que tornar interessante o mais importante. Tudo se torna mais fácil quando o nosso interlocutor está interessado, até mesmo curioso e fica entretido. Aqui reside a arte do químico. Afinal, o público em geral pode também aprender Ciências pelas Artes.

\begin{abstract}
Manuel João Monte é Professor Associado, atualmente convidado do Departamento de Química e Bioquímica da Faculdade de Ciências da Universidade do Porto onde leciona há mais de $\mathbf{4 0}$ anos. É coordenador do grupo de investigação em Termodinâmica Molecular e Supramolecular do Centro de Investigação em Química da UP (CIQUP). Publicou mais de 100 artigos em revistas científicas internacionais com avaliação por pares $\mathrm{e}$ é o autor de $O$ Bairro da Tabela Periódica, Arsenicum e, mais recentemente, de Que Coisa é o Mundo (no prelo).
\end{abstract}

\begin{abstract}
Como e quando surgiu o seu gosto pela Química?

Foi por acaso. Como muitas das coisas que me aconteceram na vida, não pensei muito. Talvez tenha sido levado pelos meus colegas e amigos de liceu, especialmente o Vicente Campo, que me induziram a ingressar em Engenharia Química na Universidade do Porto. Não tive influências familiares. Também tenho um espírito aventureiro herdado do meu pai, que correu mundo como marinheiro.
\end{abstract}

\section{Gostava que caracterizasse o seu percurso} académico e profissional.

Entrei para Engenharia Química na Universidade do Porto em 1969, que frequentei até metade do $4 .^{\circ}$ ano (o curso tinha cinco anos). Nesta fase do meu percurso 
percebi que o que queria mesmo era fazer investigaç̧ão e, por isso, interrompi o curso de Engenharia Química. Por essa altura fui para Inglaterra, para uma vila perto de Southampton, onde estive durante cerca de dois meses. Tinha uma grande paixão pela música e tocava em bandas de música desde os 16 anos. Acabei por participar na banda de música onde a minha amiga inglesa Cindy era vocalista. Recordo vivamente esta etapa da minha vida, mas tive de regressar a Portugal pois estava adiado ao Serviço Militar Obrigatório para estudar na Universidade e, caso não regressasse, podia ir para a guerra, situação que queria evitar. Já no Porto decidi pedir um plano de equivalência à Faculdade de Ciências para o curso de Química. Tive poucas equivalências, teria de frequentar quatro dos cinco anos, mas decidi ingressar no curso. No final do $3 .^{\circ}$ ano (bacharelato) começaram a surgir convites de alguns professores para ingressar no ramo científico, nomeadamente dos professores João Cabral (Química Analítica), Adélio Machado (Química Inorgânica) e Ribeiro da Silva (Química-Física). Relembro que, na altura, o professor Ribeiro da Silva convenceu-me (ele era um líder motivador) a desenvolver um projeto de construção de um novo equipamento para a medição de pressões de vapor. E, tanto quanto eu sei, os primeiros resultados de pressão de vapor em Portugal foram da nossa autoria. Tinha construído um equipamento de raiz, ainda como estudante da licenciatura. Conhecia bem cada pedaço das tripas mais escondidas do novo aparelho de efusão de Knudsen. Estávamos em 1981, o ritmo de publicação era muito diferente do atual e os detalhes do novo aparelho só foram publicados em 1990, na Thermochimica Acta. Em dezembro de 1979 fui contratado como monitor e, em 1980, comecei a lecionar aulas laboratoriais da licenciatura. Ingressei no Centro de Investiǵação em Química da UP em 1981, tendo sido contratado como Assistente Estagiário em 1982 e, em 1985, como Assistente. Seguiu-se um período de três anos de dispensa de serviço docente, com uma bolsa para a realização de trabalho de doutoramento em Química que conluí, na especialidade de Química-Física, em dezembro de 1990, sendo contratado, nessa data, como Professor Auxiliar. O título da minha Tese foi Aplicação de Técnicas de Efusão à Determinação de Entalpias de Sublimação. Por concurso público, fui contratado como Professor Associado (com nomeação definitiva) em 2002. Durante vários anos acumulei a docência e a investigaação com tarefas administrativas de que destaco as alterações dos estatutos da FCUP no âmbito do Conselho de Representantes e a transição para Bolonha. Desempenhei vários cargos de relevo, como por exemplo: Presidente do Departamento de Química (2005-2006), Vice-Presidente do Conselho Científico da FCUP (2008-2010), Membro do Conselho Geral da UP (2009-2013) e Presidente do Conselho de Representantes da FCUP (2017-2018).

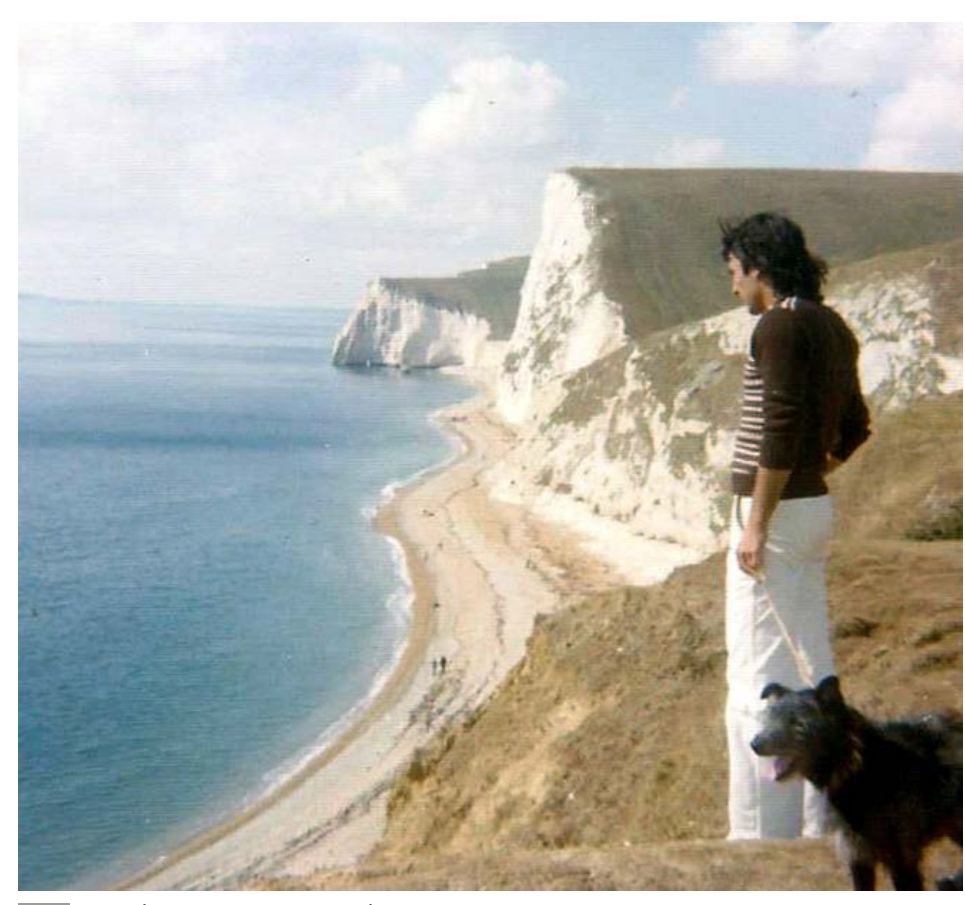

Manuel João Monte na Costa do Dorset, agosto de 1976, com o Toby (o cão da amiga Cindy).

M-3065

J. Chem. Thermodynamics 1995, 27, 175-190

Vapour pressures and standard molar enthalpies of sublimation of seven crystalline copper(II) $\beta$-diketonates. The mean molar $(\mathrm{Cu}-\mathrm{O})$ bond-dissociation enthalpies

Manuel A. V. Ribeiro da Silva, Manuel J. S. Monte, Centro de Investigação em Quimica, Department of Chemistry, Faculty of
Science. University of Porto, P-4000 Porto, Portugal -4000 Porto, Portugal

and Jan Huinink

Department of Interfaces and Thermodynamics, Debye Institute, Utrech University, Padualaan 8, $3584 \mathrm{CH}$ Utrecht, The Netherlands

(Received 8 July 1994)

Comparação do trabalho de Manuel João Monte utilizando os aparelhos de Utrecht com o equipamento do Porto. DOI: 10.1006/jcht.1995.0014.

\section{Nas suas publicações científicas aparecem maioritariamente os termos Thermodynamic(s) e Vapour Pressure. Que lugar ocupa a termodinâmica e a pressão de vapor na sua vida?}

Representam muita dedicação. A determinada altura senti que o trabalho experimental que realizava estava a tornar-se algo repetitivo. Descobri que o desenvolvimento de correlações, traduções matemáticas dos resultados obtidos experimentalmente, podiam ser um bom desafio para me animar e assim foi. Tinha muitas perspetivas para calcular e estimar entalpias 
66

Alguns teóricos colecionam dados e não rastreiam a qualidade que lhes é inerente. Continua a existir muito ruído científico criando um mar de lixo e as correlações podem ficar enviesadas. É imperioso saber escolher os melhores resultados, os de maior qualidade.

\footnotetext{
de evaporação, entalpias de sublimação, pressões de vapor, energias de Gibbs. 0 meu objetivo era também discernir os melhores resultados para as pressões de vapor. Alguns teóricos colecionam dados e não rastreiam a qualidade que lhes é inerente. Continua a existir muito ruído científico criando um mar de lixo e as correlações podem ficar enviesadas. É imperioso saber escolher os melhores resultados, os de maior qualidade. Mas foi nos Países Baixos, na Universidade de Utrecht, que avancei bastante nesta área e onde tomei contacto com outras realidades totalmente diferentes. Nesta universidade existia uma gestão empresarial. Fechavam e abriam grupos de investigação com muita facilidade. Mas o Grupo de Termodinâmica da Universidade de Utrecht, onde realizei quatro estágios no grupo de C. G. de Kruif (falecido em 2016), era de elevado nível e manteve-se ativo durante várias décadas, mas já não existe.
}

Há algum momento/passagem que gostaria de destacar nos seus trabalhos? Qual? Quais?

Há vários momentos. Destaco a satisfação da publicação do primeiro artigo (J. Chem. Thermodynamics, 1999) em que fui autor correspondente, os três artigos de construção de novos equipamentos (Thermochim. Acta, 1990; J. Chem. Thermodynamics, 2006; J. Chem. Eng. Data, 2006), e a determinação de propriedades termodinâmicas do TCA e de outros compostos análogos que prejudicam a qualidade dos vinhos. Muito importante foi também a orientação de várias teses de Mestrado e das três estudantes de Doutoramento que acabaram com sucesso as suas teses - a alemã Dorothea Hillsheim (UP, 2002) e as portuguesas Ana Rita Almeida (UP, 2013), atualmente investigadora no meu Grupo, Juliana Oliveira (UP, 2016) e as orientações de pós-doc da Ana Rita e do checo Michal Fulem. A Dorothea, após finalizar o doutoramento, foi para os EUA como pós-doc do meu colega americano James Chickos.

\begin{abstract}
Quais os países com que tem mais colaboração? Destaco talvez os EUA, com o professor James Chickos, de St. Louis, Missouri, que utiliza uma técnica de determinação de pressões de vapor e entalpias com recurso à cromatografia em fase gasosa, o que permite determinações em compostos com baixo grau de pureza. Trocamos e-mails com discussões interessantes e temos convivido em vários momentos (congressos, cursos NATO, etc.), em vários países (Portugal, EUA, Rússia, Alemanha, Áustria, etc.). Colaborei com o prestigiado Instituto de Química Tecnológica de Praga (República Checa) orientando um pós-doc (Michal Fulem) em aulas Erasmus com estágios de duas estudantes de doutoramento checas. Como já referi, foi também extremamente importante a colaboração com Utrecht (Países Baixos) durante os meus quatro estágios entre 1985 e 1988.
\end{abstract}

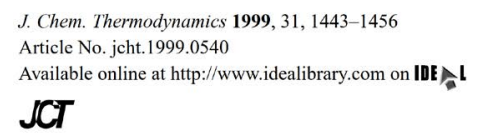

Vapour pressures, enthalpies and entropies of sublimation of trans-cinnamic acid and of nine methoxy and dimethoxycinnamic acids

Manuel J. S. Monte ${ }^{a}$ and Dorothea M. Hillesheim Centro de Investigação em Quimica, Department of Chemistry, Faculty of Science, University of Porto, Rua do Campo Alegre 687, P-4169-007 Porto, Portugal

0 primeiro artigo de Manuel João Monte em que é auto correspondente. DOI: 10.1006/jcht.1999.0540.

\section{Manuel João Monte tem um gosto especial por este trabalho em colaboração com diferentes instituições. Foi publicado num número especial da revista homenageando os autores mais citados. DOI: 10.1021/acs.jced.9b00062.}

tournal.of

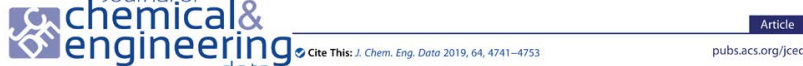

Thermodynamic Properties of Moldy-Musty Contaminants of Wine Ana R. R. P. Almeida, ${ }^{\dagger}{ }^{\circ}$ Bruno D. A. Pinheiro, ${ }^{\dagger}$ Carlos F. R. A. C. Lima, ${ }^{\dagger}$ Ana Filipa L. O. M. Santos, António C. S. Ferreira, ${ }^{\ddagger}$ Filipe A. Almeida Paz, ${ }^{8}$ and Manuel J. S. Monte ${ }^{*+\uparrow}$

'Centro de Investigação em Quimica (CIQUP), Department of Chemistry and Biochemistryy, Faculty of Science, University of Porto, Rua do Campo Alegre, 687, P-4169-007 Porto, Portugal

${ }^{4}$ Cork Supply Portugal, SA, Rua Nova do Fial, no. 102, 4535-465 São Paio de Oleiros, Portugal "CICECO - Aveiro Institute of Materials, Department of Chemistry, University of Aveiro, Campus Universitário de Santiago, 


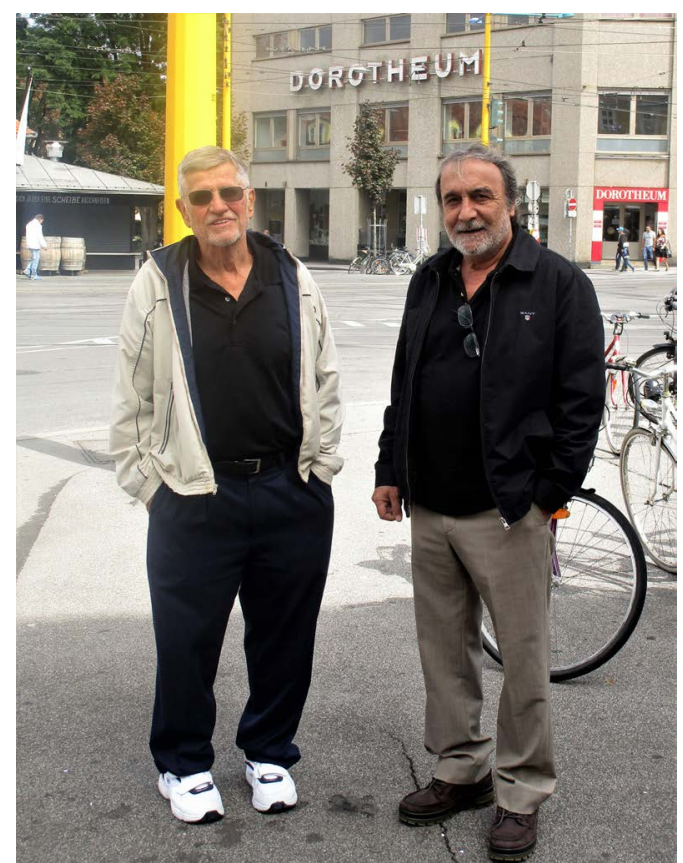

Manuel João Monte com James Chickos durante un congresso em Graz (Áustria, 2017). Esta foto foi enviada à Dorothea - o edifício ao fundo chama-se Dorotheum!

Quais os aspetos mais relevantes e que benefícios para a sociedade é que o seu trabalho nesta área nos pode trazer?

Preocupo-me bastante com os processos de mobilidade ambiental de poluentes (como os pesticidas). Há propriedades (volatilidade, solubilidade, etc.) que têm de ser conhecidas para se prever a mobilidade e o destino desses compostos no meio ambiente.

\section{6}

A ciência fundamental é importante, mas não é tudo e cada vez mais temos de ter uma investigação direcionada para problemas societais. Existem vários desafios onde a Química pode ser personagem importante na resolução prática dos problemas do nosso tempo.
Fale-nos de um momento muito importante na sua carreira, experiências administrativas ou atividades de gestão universitária.

A presidência do Departamento de Química da Faculdade de Ciências da Universidade do Porto (2005-2006) que incluiu o processo de Bolonha, a revisão dos estatutos da Faculdade onde se incluiu a redução do número de departamentos, a Presidência do Conselho de Representantes da FCUP (2017-2018) e pertencer ao primeiro Conselho Geral da UP (2009-2013).

Indique-nos os seus químicos de referência.

Há uns anos poderia ter referido Lavoisier, mas depois de estudar melhor a personagem, passei a preferir o russo Mikhail Lomonosov (1711-1765), que se antecipou a Lavoisier em cerca de duas décadas, no princípio da conservação da massa em reações químicas e na refutação da Teoria do Flogisto. Além de químico, era um brilhante polímato e foi considerado o pai da poesia e ciências russas. Refiro Roald Hoffmann, pelo prémio Nobel da Química em 1981, pela sua investigação e poesia - são dele os versos: Men (and women) are not / as different from molecules / as they think. Também Carl Djerassi, inventor da pílula contracetiva, mas amante da dramaturgia. Conhecia-o muito bem e fui o seu padrinho de Doutoramento Honoris Causa (UP, 2011). Faleceu em 2015 com 91 anos e era uma pessoa extraordinária. E, para completar o quarteto dos químicos amantes das artes, acrescento Jorge Calado, um grande divulgador que, sem o saber, me conduziu ao teatro. Quero ainda salientar o professor Ribeiro da Silva, uma pessoa "viciada" em trabalho (workaholic), muito metódico e rigoroso e um grande orientador e motivador.

Quantas pessoas constituem o seu grupo de investigação?

Atualmente somos seis docentes e três investigadores.

Que mensagem gostaria de deixar aos jovens investigadores portugueses?

A ciência fundamental é importante, mas não é tudo e cada vez mais temos de ter uma investigação direcionada para problemas societais. Existem vários desafios onde a Química pode ser personagem importante na resolução prática dos problemas do nosso tempo. Destaco o problema grave das alterações climáticas, em resultado do aquecimento global, onde a contribuição da água (um incontornável gás de estufa condensável) não tem sido considerado com a relevância que the atribuo, na generalidade dos modelos interpretativos do fenómeno. 


\section{6}

\section{A cultura científica em Portugal pode beneficiar da experiência dos mais velhos, ainda com atividade intelectual saudável, como veículo de transferência de conhecimento e de orientação dos mais jovens.}

\author{
Como caracteriza o acesso ao \\ financiamento na área que escolheu para \\ desenvolver a sua investigação? \\ Não tenho tido razão de queixa e não me tenho sentido \\ limitado para trabalhar.
}

Que análise faz sobre a cultura científica em Portugal?

É difícil responder. Penso que a cultura científica em Portugal ainda é modesta. Perdem-se vários talentos jovens que procuram trabalho fora. Perde-se sangue novo e perde-se também muito conhecimento com algumas aposentações. Quando um cientista se reforma liberta-se de cargos administrativos, da lecionação, de várias responsabilidades. Ganha independência e o seu pensamento mais liberto conduz necessariamente ao desenvolvimento e à criação de conhecimentos maduros e rigorosos. Nesta situação que refiro há casos extremos como a tristeza de Roald Hoffmann quando há dois anos Ihe fecharam o Centro de Investigação em Cornell, com o despedimento de todos os investigadores, e a alegria de James Chickos que diariamente continua a orientar o seu grupo em St. Louis, apesar dos seus 80 anos. Afinal, a cultura é uma herança de saberes. A cultura científica em Portugal pode beneficiar da experiência dos mais velhos, ainda com atividade intelectual saudável, como veículo de transferência de conhecimento e de orientação dos mais jovens.

A Química é útil, engraçada, perigosa, estimulante, frustrante, mas é indispensável. A Química tem um papel fundamental na Sociedade, mas frequentemente é acusada de efeitos nefastos, ou seja, dizem que isso tem Químicos! Na sua opinião como se deve reverter esta ideia para repor a verdade dos factos, pois afinal é a Química que nos governa a Vida?

Desenganando os mal informados, explicando que há modas que não fazem sentido. Atualmente o que é natural está na moda! Claro que há produtos naturais venenosos, alguns mortais. Em rigor trata-se de um problema de cultura científica. Veja o desenvolvimento económico e social proporcionado pelos polímeros que presentemente são os maus da fita. Preocupa-me o lixo ambiental nalgumas zonas do globo, preocupam-me as difamações à Química. Será que a culpa é dos Químicos? Veja o caso dos medicamentos, dos antibióticos... quantos milhões de vidas se pouparam graças aos medicamentos? Quanta fome se evitou graças aos fertilizantes? A população mundial nunca foi tão elevada, mas também nunca se viveu tão bem! Fazendo uma retrospetiva, posso afirmar que o progresso da sociedade se deveu à evolução positiva da Química.

Todos os anos são proclamados pelas Nações Unidas "Os Anos Internacionais de...”. Como é que a Sociedade celebra estes temas? Há comunicação/ divulgação suficiente? 2019 foi o Ano Internacional da Tabela Periódica. Estarão os portugueses cientes que a química contribui decisivamente para a satisfação das necessidades da sociedade moderna? Será que a sociedade se esqueceu dos problemas do planeta existentes em dezembro de 2019? Como é que a SPQ pode interferir? Estarão reunidas as condições para que a Química assuma rapidamente algum papel principal?

A Química tem um papel central e todos dependem dos progressos dos químicos. A Química devia ter um papel mais forte, com mais responsabilidades. A biologia, a física e a geologia estabelecem interações muito facilmente com a Química. Espero, num futuro próximo, mais intervenção de homens e de mulheres que não são tão diferentes das moléculas como julgam, para citar Roald Hoffmann.

Como surgiu a ideia de $O$ Bairro da Tabela Periódica? A inspiração deverá ter surgido numa reunião de condomínio...!

Não foi. Aconteceu durante a programação do Ano Internacional da Tabela Periódica, em conversa com a Professora Ana Cristina Freire, à data presidente do Departamento de Química da FCUP. Tinha colegas que referiram o evento Global Women Breakfast realizado a 12 de fevereiro de 2019 à escala g'obal. Este evento promoveu o convívio entre mulheres 
de toda comunidade académica, de várias faixas etárias, docentes, não docentes, investigadores e discentes (dos vários ciclos de estudo) de vários Departamentos da minha Faculdade. Pensei, ... são mulheres a comemorar um conjunto de elementos todos masculinos (na altura até me esqueci da prata e da platina...), vou gozar com isto. E foi assim que aconteceu - decidi humanizar os elementos químicos organizados nos seus quatro blocos, em famílias como se fosse um prédio, um condomínio, e onde discutem as suas diferentes afinidades. Também aproveitei para enfatizar questões de género que, no passado, muito discriminaram as mulheres na ciência. Para compor a obra adicionei cenas de aulas no ensino secundário sobre a Química e a sobre a Tabela Periódica.

\section{Como encarou o prémio da Sociedade Portuguesa de Autores, recentemente atribuído?}

Com uma grande surpresa pois não conhecia o prémio. Recebi a notícia através de um telefonema da SPA. Dadas as circunstâncias da COVID-19, o prémio abarcou os anos 2019 e 2020 . Além de surpreendido, senti-me muito honrado pois é um prémio muito prestigiante.

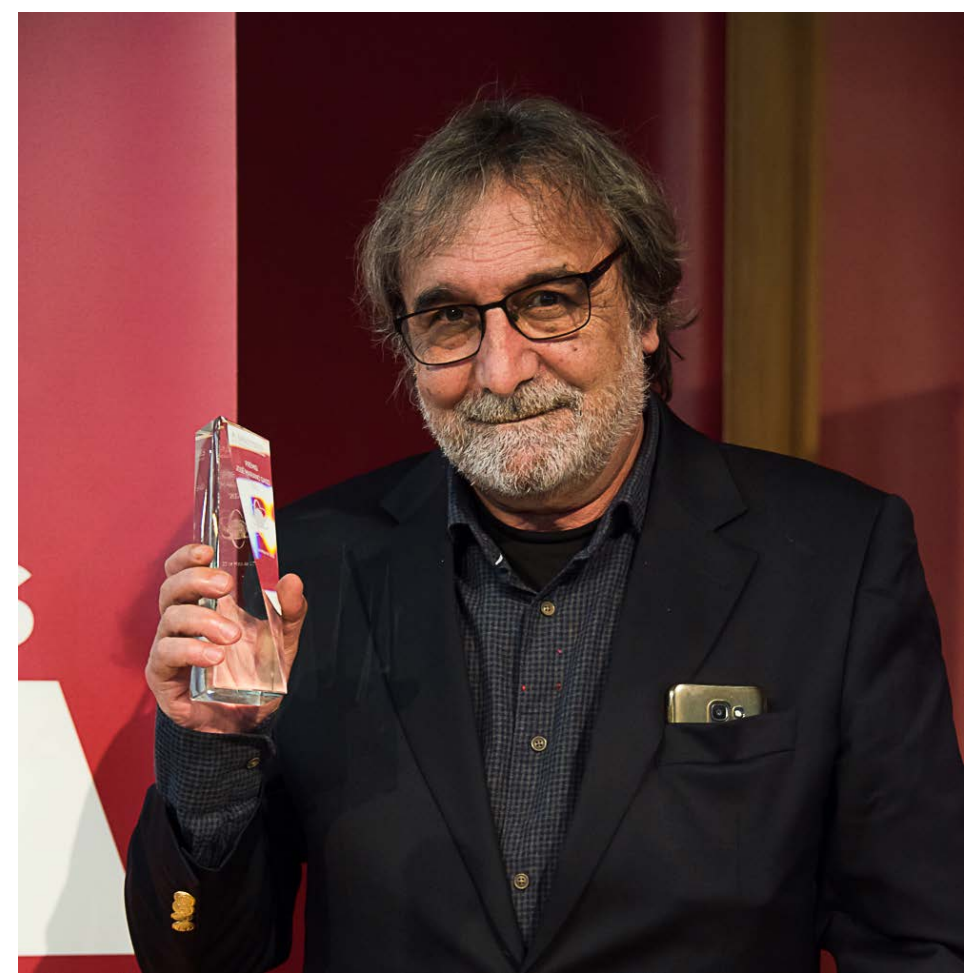

Entrega do prémio José Mariano

Gago no dia 25 maio de 2021 por ocasião do $96 .{ }^{\circ}$ aniversário da SPA.

\section{Como é que os seus colegas falam de química consigo?}

Continua tudo normal apesar de receber elogios a esta nova faceta de dramaturgo na minha vida. Os meus colegas acham graça ao lado lúdico.

\section{Que influências estão na origem desta faceta da sua vida de químico?}

Posso referir uma palestra na reitoria da Universidade do Porto, em 2004, pelo Professor Jorge Calado, cujo título era 0 dia em que a Química nasceu. Gostei bastante. Jorge Calado recomendou aos ouvintes lerem o livro Oxygen: A Play in 2 Acts, de Carl Djerassi e Roald Hoffmann. Gostei de o ler e contactei Carl Djerassi para fazer a tradução do livro para português, o que veio a acontecer (à data não sabia que existia uma versão brasileira). 0 grupo de teatro do Campo Alegre, por intermédio do encenador Júlio Cardoso encenou a representação. Mais tarde, embarcámos na Falácia sobre a ética na Ciência, uma peça moralista, audaciosa. Eu gosto muito do estilo de diálogo destes livros que se convertem com facilidade em peças de teatro.

\section{O que se pode fazer para garantir que mais jovens descubram o prazer da leitura?}

Produzir diálogos soft, livros com poucas páginas, leitura entusiasmante, concisa e com algum humor (como faziam os antigos filósofos gregos). Em geral, os jovens não têm paciência para longas leituras (eu também já não tenho).

\section{A igualdade de género foi uma preocupação ao longo da sua carreira na Universidade do Porto. Pode dizer-nos o que já perdemos com esta desigualdade?}

Posso dizer-lhe que nunca notei vincadamente esta desigualdade. Interessei-me mais com esta realidade na lig̉ação à História das Ciências e à História da Química, que ainda leciono, ao constatar que, no passado, foram cometidas graves injustiças relativamente ao acesso das mulheres à educação e à investigação em ciência e que se perderam 50\% do potencial de conhecimento (admitindo uma divisão entre homens e mulheres de $50 \% / 50 \%$ ). Até aos inícios do século $X X$, as mulheres eram proibidas de frequentar a maior parte das Universidades. Esta situação representou um prejuízo enorme nas Ciências. Ora isto é revoltante.

\section{O que é que já aprendemos com a atual pandemia de COVID-19?}

Não sei se vamos aprender algo. Somos sistemas abertos e somos parte integrante da natureza, e podemos ser considerados uma praga ambiental porque somos cada vez mais no nosso planeta. Quando uma parte da 
66

O futuro do ensino deve ser presencial, sempre nos laboratórios. Os alunos têm de mexer nos equipamentos. Não se pode perder a ciência experimental, mas no futuro ambos os métodos (à distância e presencial) parecem razoáveis e complementares.

natureza está doente, toda a natureza é prejudicada. E nós estamos doentes, não só da pandemia, mas também pelo desrespeito com que temos tratado a nossa casa comum. A natureza está ferida e revoltada.

O que considera que vai mudar agora depois desta pandemia?

Receio que o turismo vá ser muito afetado, o que é economicamente grave pois, no fundo, o turismo tem sido um importante motor da nossa economia.

E por falar em turismo, que local recomenda visitar? Algum museu em especial?

Para nós, químicos, sem dúvida a casa museu de Mendeleev na Universidade de São Petersburgo, onde se consegue respirar aquela época, mas também o colossal Hermitage. Sobre artes, também Moscovo, Praga, e outras cidades checas (o museu de Egon Schiele, em Český Krumlov), Amesterdão com o museu Van Gogh e os Rembrandt do Museu Estadual, etc.

O que vai ser para si o futuro do ensino? À distância ou presencial?

0 futuro do ensino deve ser presencial, sempre nos laboratórios. Os alunos têm de mexer nos equipamentos. Não se pode perder a ciência experimental, mas no futuro ambos os métodos (à distância e presencial) parecem razoáveis e complementares.

Para além do atual trabalho de investigação e como docente aposentado, ainda está envolvido noutras vertentes como é o caso dos hobbies. Gostaria de referir-se sumariamente a essas atividades e a satisfação pessoal que retira de cada uma delas?

Recentemente o meu hobby principal é escrever, tocar um pouco de piano ou guitarra, fotografar e cozinhar. Também gosto muito de passear a minha cadela. Tenho uma paixão especial por cães.

Indique-me um livro, uma música e um filme/teatro da sua preferência.

Teatro - O Bairro da Tabela periódica (evidentemente). Uma música... difícil. Adoro Händel com a sua Water Music. Mas muito, muito mais. Não caberiam aqui... Um livro, pode ser The Hidden Life of Trees, de Pete Wohlleben (suponho que já há uma tradução portuguesa). Passei a olhar as árvores de maneira diferente.

Na sua relação com a gastronomia, o equilíbrio está mais deslocado para o lado dos sólidos ou dos líquidos? Quais os melhores pratos?

Mais para o lado dos sólidos. Também gosto de um bom copo de vinho tinto e de cerveja. Gosto de pratos de bacalhau. E gosto de cozinhá-los.

Qual foi a melhor viagem que fez?

Foi à Rússia: Moscovo em 2006 e São Petersburgo em 2019. Mas, em tempos idos, as aventureiras viagens de carro (sozinho e sem GPS) aos Países Baixos, República Checa, Alemanha, Polónia, etc.

Qual é o seu lema de vida/lema de vida profissional/missão para a sociedade? Consciência de ser parte sentida na natureza.

Acha que a sua vida dá uma peça teatro? Não só a minha como a de todos nós. Somos únicos e temos vidas únicas que dariam um guião para uma peça de teatro.

E quem gostaria que fosse o encenador? Os que melhor conheço: Júlio Cardoso ou Mário Montenegro.

A cortina começa a fechar-se e os autores estão a posicionar-se no palco para agradecer ao público. Ao longe ouvem-se palmas. As vénias repetem-se e aumenta o som produzido pela ovação. Já de pé e alinhados preparam-se para abandonar o teatro e esperam voltar novamente à cena. João, foi um gosto conversar consigo nesta Interação Química. Fazemos votos para que volte à cena. Muito obrigado e mais uma vez MUITOS PARABÉNS.

(realizado em 7 de julho de 2021) 